\title{
Minimally Invasive Intervention for Primary Caries Lesions: Are Dentists Implementing This Concept?
}

\author{
Mark Laske $^{a} \quad$ Niek J.M. Opdam ${ }^{a} \quad$ Ewald M. Bronkhorst ${ }^{a} \quad$ Jozé C.C. Braspenning ${ }^{a}$ \\ Wil J.M. van der Sanden ${ }^{a}$ Marie Charlotte D.N.J.M. Huysmans ${ }^{a}$ Josef J. Bruers ${ }^{b, c}$ \\ ${ }^{a}$ Radboud university medical centre, Department of Dentistry, Radboud Institute for Health Sciences, Nijmegen, \\ The Netherlands; ${ }^{\mathrm{b}}$ Academic Centre for Dentistry Amsterdam (ACTA), Department of Social Dentistry and \\ Behavioural Sciences, University of Amsterdam and VU University, Amsterdam, The Netherlands; ' Department of \\ Research and Information, Royal Dutch Dental Association (KNMT), Utrecht, The Netherlands
}

\section{Keywords}

Minimally invasive dentistry · Primary caries · Questionnaire . Restorative dentistry $\cdot$ Treatment planning

\begin{abstract}
Contemporary minimally invasive treatment concepts for restorative treatment of primary caries lesions include both delayed intervention and smaller-sized preparations restricted to removal of carious tissue. The aim of this study was to investigate whether these concepts have resulted in a trend towards a more conservative choice made by dentists regarding treatment thresholds and restorative techniques. The results from previously conducted, precoded questionnaires developed by Espelid and Tveit, as well as from a recent Dutch questionnaire, were collected and analysed. A worldwide trend towards more minimally invasive strategies in the operative treatment of caries lesions could not be observed, neither for the initiation of operative treatment nor for the preparation techniques. However, in some countries, changes over time could be assessed, especially in Norway, where a reduction in the proportion of interventions is visible for both occlusal and approximal lesions, indicating that more dentists are postponing interventions until
\end{abstract}

the lesions have progressed to a deeper level. From the Dutch national survey, it could be concluded that operators that intervene at an earlier stage of approximal lesioning (stage $\leq 4$ ) also intervene at an earlier stage of occlusal caries (stage $\leq 3)(p=0.012 ; \mathrm{OR}=2.52 ; 95 \% \mathrm{Cl}: 1.22-5.22)$. Generally, it can be concluded that dentists worldwide still tend to operatively intervene at a too early stage of caries, although variations exist between countries. A worldwide shift could be observed in the restorative material applied, since composite resin has almost completely replaced amalgam for restoring primary caries lesions.

(C) 2018 The Author(s)

Published by S. Karger AG, Basel

\section{Introduction}

Despite the fact that the prevalence of dental caries has decreased over the past decades, it still remains one of the most prevalent diseases worldwide [Marcenes et al., 2013]. Dental caries has a great impact on the global clinical and economical burden [Kassebaum et al., 2015; Listl et al., 2015] and caries management is a main issue in oral healthcare. 
Prior to the late 1970s, caries progression in dentin was considered to be a rapid and irreversible process, and the concept of arresting caries lesions was not well adopted yet [Vidnes-Kopperud et al., 2011]. In the early 1980s, studies first showed that caries was indeed a slowly progressing disease, which initiated a more preventive, nonoperative concept for its treatment [Pitts, 1983; Gröndahl et al., 1984]. Nowadays, it is commonly accepted that a low-cariogenic diet and adequate oral hygiene by brushing with fluoride-containing toothpaste can control or arrest progressive demineralization and caries lesion progression [Frencken et al., 2012]. As a result, increased emphasis is placed on the concept that caries should be managed using non-invasive preventive methods as much as possible [Vidnes-Kopperud et al., 2011; Schwendicke et al., 2016].

However, absence or failure of preventive management will still lead to a need for operative intervention. During the last decades, a minimally invasive treatment concept for caries lesions has been introduced. This includes both delayed intervention [Meyer-Lueckel and Paris, 2016] and smaller-sized preparations restricted to removal of carious tissue only, instead of the "extensionfor-prevention" treatment concept. Moreover, the choice of restorative material for restoring caries lesions has changed too, from amalgam towards adhesive toothcoloured materials, mainly composite resin. The use of adhesive techniques made it possible to use less invasive preparation designs, restricted to removing only carious tissue; traditional retentive amalgam preparation forms were abandoned, while for proximal lesions saucershaped preparations were introduced. Tunnel restorations for proximal lesions were explored too, but they have been proven to be unsuccessful [Nicolaisen et al., 2000; Strand et al., 2000; Hörsted-Bindslev et al., 2005].

The decision to intervene operatively in the treatment of carious lesions is based on diagnosis by visual and tactile inspection for occlusal caries, while bitewing radiography is mainly employed for the diagnosis of approximal caries [Kidd and Pitts, 1990; Lussi, 1991; Penning et al., 1992]. Based on the presence of discoloured or cavitated fissures and translucencies on radiographs, dentists decide when and how to treat a caries lesion. Espelid et al. $[1985,2001]$ developed questionnaires to investigate dental restorative treatment thresholds and strategies, which since then have been employed in several countries showing a wide variation of outcomes [Innes and Schwendicke, 2017]. There seems to be a tendency towards a more minimally invasive strategy for the treatment of primary caries lesions, but this has not been established yet. The outcomes of surveys should be compared over time - and, if possible, within countries - since tendencies might be different around the world.

The only available results regarding decision-making on the restorative treatment of primary caries lesions from the Netherlands date back to 1983, and they focused on approximal lesions only [Mileman and Espelid, 1988]. To investigate current Dutch decision-making by general practitioners on the treatment of occlusal and approximal caries lesions, the survey was repeated. The aim of this study was to investigate if there are trends towards a more conservative, minimally invasive treatment concept for primary caries as measured by treatment thresholds and the choice of restorative techniques made by dentists.

\section{Materials and Methods}

\section{Study Population and Design}

The precoded questionnaires developed by Espelid et al. [1985, 2001] have been used in several previous studies around the world. These questionnaires include figures or photographs of different stages of approximal [Espelid et al., 1985] and occlusal lesions [Espelid et al., 2001] and questions about restorative treatment criteria, preparation techniques and the use of restorative material.

Approximal caries progression was divided into 6 stages: (1) outer half of the enamel, (2) inner half of the enamel, (3) enameldentin border, (4) outer third of the dentin, (5) outer half of the dentin and (6) inner half of the dentin. Traditional black class II preparation, tunnel preparation or saucer-shaped preparation were the options for approximal preparation. Occlusal caries progression was divided into 5 stages: (1) white or discoloured enamel, (2) small cavitation clinically, (3) moderate-sized loss of tooth structure, (4) large-sized loss of tooth structure and (5) extensive loss of tooth structure. For occlusal preparations, only carious tissue removal, opening the whole fissure or another preparation of preference could be chosen.

Amalgam, glass ionomer, composite resin, compomer or another material of preference could be chosen as the approximal or occlusal restorative material. All of the included studies had the same design and were based on an identical questionnaire, which, due to translation into other languages, showed different descriptions of the stages of caries, although the figures were identical in all cases. The questionnaires were sent to general practitioners, presenting an identical outcome: the decision taken by the dentist.

To compare them through time and between different countries, the results of the current Dutch questionnaire and of all previously published articles based on these questionnaires were collected and analysed.

\section{Dutch Survey}

The questionnaire, based on the questionnaires by Espelid and Tveit [Espelid et al., 1985, 2001], was sent electronically to a sample of 1,050 Dutch dentists in June 2015. Based on the size of the dentist population in the Netherlands of around 8,500 dentists, a desired level of confidence of $95 \%$ and an estimated degree of dispersion of $30 \%$ require a sample size of 311 . Taking into account the 
Fig. 1. Cross table of the number of Dutch respondents selecting specific thresholds for operative treatment in occlusal and approximal caries cases. As the stages at either end of the spectrum were very rarely chosen, these were merged with the adjoining stages for the table. However, the individual numbers are shown in parentheses in the cells showing the total numbers.

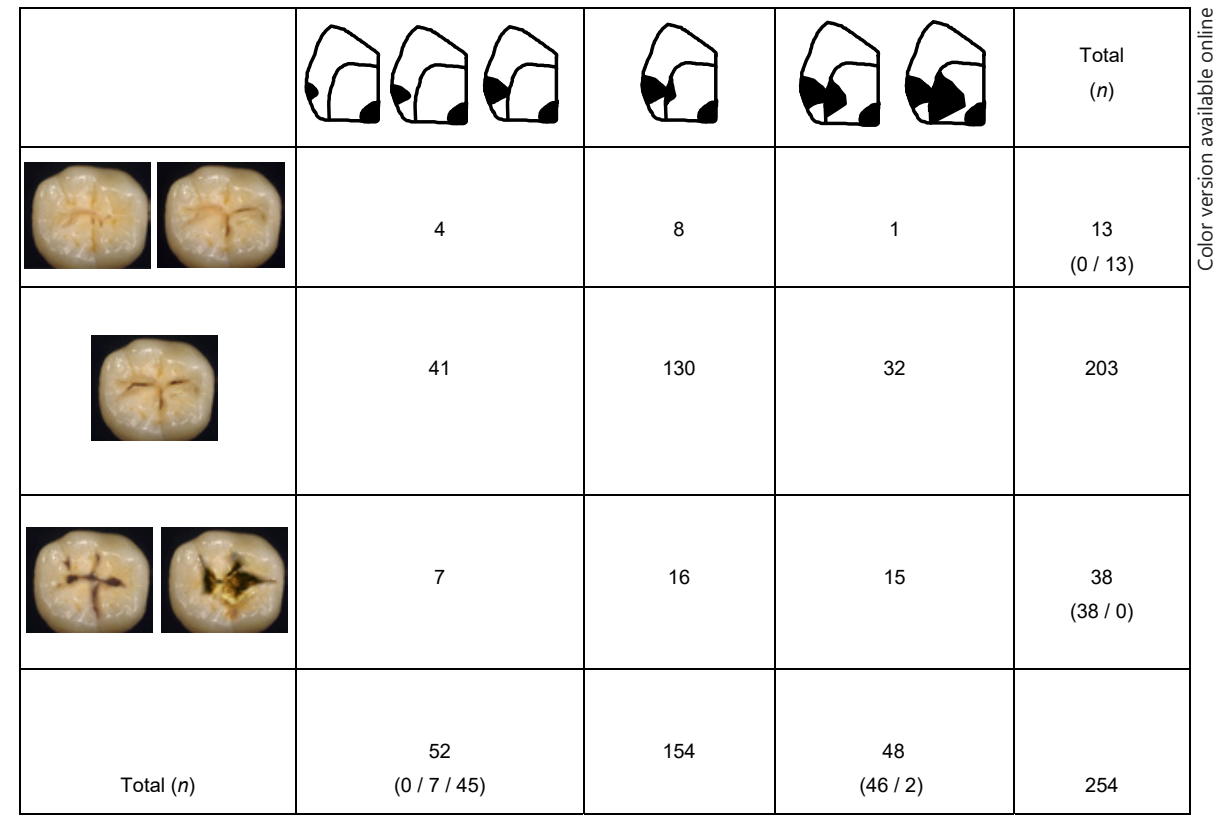

circumstance that a number of email addresses are not reachable (bouncing) and the experience that about 25-30\% respond to Web surveys, 1,050 Dutch dentists were approached. The sample was drawn randomly by the Royal Dutch Dental Association (KNMT) from the national population of registered dentists aged 64 years or younger with a known address in the Netherlands. Participation was voluntary and anonymous, and no compensation was offered to the respondents. Reminders were sent after 1 week, 3 weeks and 13 weeks. Dentists who were not involved in patient treatment and respondents who did not complete the questionnaire were excluded. Information on the respondents regarding gender, years of experience (divided into groups of $1-5,6-15,16-30$ and $\geq 31$ years) and place of graduation was collected. The questions from the questionnaire that were included in the national survey and the international studies are shown in Appendix 1.

Statistical analyses were performed with IBM SPSS Statistics version 22.0 (Statistical Package for the Social Sciences; SPSS, Chicago, IL, USA). Descriptive statistics, analyses with $\chi^{2}$ testing and logistic regression analyses were performed to characterize the respondent population and present the collected information on occlusal and approximal treatment thresholds and restorative management. The significance level was set at 5\%. Logistic regression analyses were performed, with restoring lesions confined to the outer third of the dentin operatively, up to and including stage 3 in occlusal lesions and stage 4 in approximal lesions, as a dependent variable. Dentists' experience, gender, place of graduation, preparation technique and restorative material were set as independent variables. Variables with a $p$ value $\leq 0.3$ in the unadjusted analyses were to be entered into the adjusted logistic regression.

\section{National and International Trends}

The results of all previously published studies based on the questionnaire of Espelid and Tveit [Espelid et al., 1985, 2001] were gathered. The following background data were extracted from the included studies: year the survey was conducted, year of publica- tion, authors, country, target audience (general dental practitioners or teachers at university) and number of respondents. The evaluated outcomes were: preferred stage of caries intervention (stage 1-5 or 1-6 for occlusal and approximal lesions, respectively); preferred preparation technique (for occlusal lesions: only caries removal, opening the whole fissure or other; for approximal lesions: traditional class II preparation, tunnel preparation or saucer-shaped preparation); and preferred restorative material (amalgam, composite, glass ionomer, composite combined with glass ionomer or other).

To evaluate trends regarding decision-making on minimally invasive restorative treatment across countries and time, the proportion of dentists intervening at or before stage 3 (occlusal) or stage 4 (approximal), preferring limited preparation techniques (only caries removal for occlusal and saucer-shaped preparations for approximal), and preferring composite or amalgam restoration material was plotted against the year of the study.

To evaluate possible correlations between countries regarding occlusal and approximal intervention thresholds, preparation techniques and the preferred restorative material, Spearman's correlation coefficient was calculated and scatterplots were drawn.

\section{Results}

\section{Dutch Survey}

In total, 280 dentists responded after 3 reminders. The response rate was $27 \%$. Dentists not involved in patient treatment and those who did not complete the questionnaire were excluded from the statistical analyses $(n=26)$. The mean age of the included dentists $(n=254)$ was 47.69 years $(\mathrm{SD}=12.3) ; 34.3 \%$ were female and $65.7 \%$ male. The 
individual background characteristics of the respondents and non-respondents are shown in Appendix 2.

As shown in Figure 1, most dentists would initiate operative treatment in lesions that had progressed into the outer third of the dentin $(79.9 \%$ for occlusal lesions and $60.6 \%$ for approximal lesions). None of the respondents would intervene at stage 1 or wait until stage 5 for occlusal lesions, and only 2 respondents reported waiting until stage 6 for approximal lesions. For approximal lesions, $20.5 \%$ of the dentists would intervene already in enamel lesions, and $15 \%$ would wait until progression had reached the middle third of the dentin. Operators that would intervene at an earlier stage of approximal lesions (stage $\leq 4)$ would also intervene at an earlier stage of occlusal caries (stage $\leq 3)(p=0.012$; OR $=2.52$; $95 \%$ CI: 1.22 5.22).

For occlusal lesions, 188 dentists $(74.0 \%)$ reported that they would only remove carious tissue, while 62 dentists (24.4\%) reported they would use the traditional wholefissure preparation. Saucer-shaped preparation was the most preferred type (59.1\%) for preparing approximal lesions, followed by traditional class II preparation (36.2\%). Tunnel preparation was only rarely reported (4.7\%). Composite resin was preferred by a vast majority of the respondents for both occlusal (92.5\%) and approximal (96.5\%) restorations. Amalgam was never reported to be the preferred material, and glass ionomer cement and other restorative materials were only rarely preferred.

The results of the regression analyses are shown in Appendices 3 and 4 . None of the independent variables was found to have a significant impact $(p<0.05)$ on the restorative threshold for stage 3 occlusal caries lesions and stage 4 approximal caries lesions, and wide confidence intervals were seen. An adjusted analysis was therefore not performed. ORs for place of graduation could not be calculated, due to the fact that the $2 \times 2$ tables contain a 0 . Therefore, this variable could not be used, and the $p$ value from the $\chi^{2}$ test was recorded.

\section{International Comparison}

The results of all published studies based on the questionnaire [Espelid et al., 2001] on occlusal caries lesion restorative treatment thresholds, preparation techniques and proposed restorative materials are shown in Table 1. The results of all published studies based on the questionnaire [Espelid et al., 1985] on approximal caries lesion restorative treatment thresholds, preparation techniques and proposed restorative materials are shown in Table 2. The stages of lesion depth were described differently in some studies marked with an asterisk $(*)$. In the study

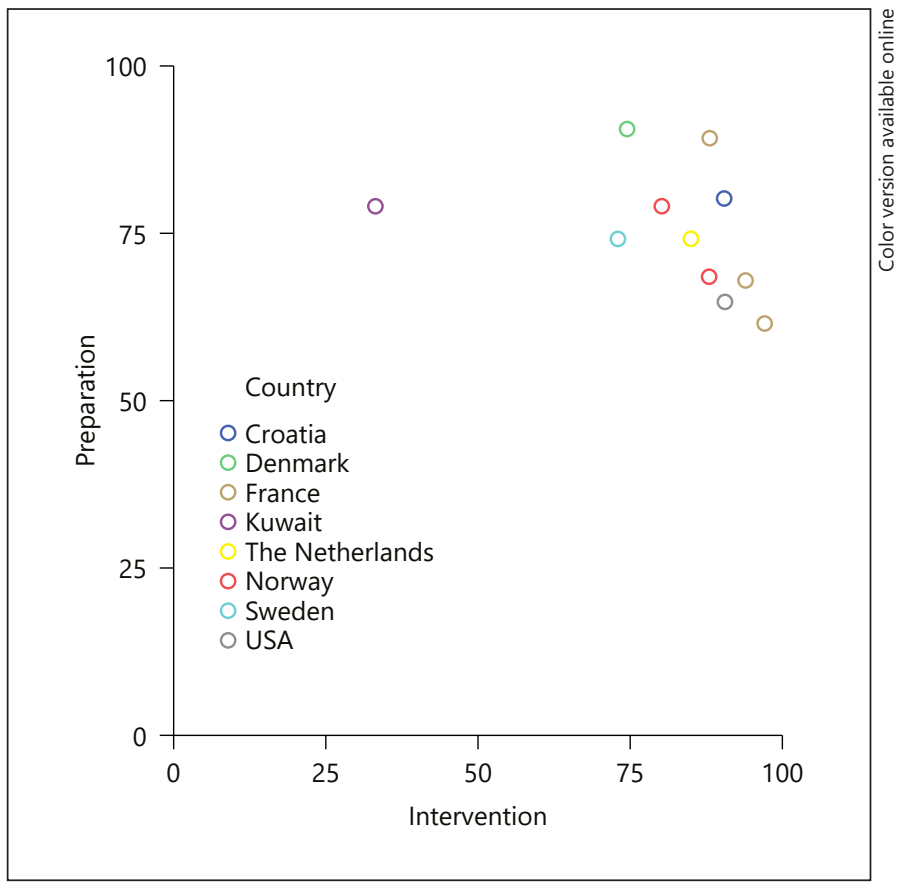

Fig. 2. Scatterplot of the percentage of respondents intervening at stage 3 occlusal caries ( $x$ axis) and the percentage of respondents choosing only caries removal as the preparation technique ( $y$ axis).

from Iran [Ghasemi et al., 2008], it was impossible to choose stage 4 in the questionnaire, and this study was therefore difficult to compare with the other studies. The studies by Kakudate et al. [2012], Gordan et al. [2009] and Heaven et al. [2013] divided the treatment thresholds for low- and high-caries-risk patients. These studies are marked with a plus sign (+), and the results for low-risk patients were selected for this study.

Figure 2 shows the correlation between the restoration threshold (stage 3) and the only-caries-removal preparation for occlusal caries lesions. This plot suggests that there is a strong tendency that when dentists are intervening at a later stage of the caries process, they are also more likely to use a minimally invasive preparation technique. However, this result is not statistically significant, as the Spearman correlation coefficient $(-0.579, p=0.062) \mathrm{did}$ not achieve the significance level set for this study (5\%). No association between the stage of intervention and the preparation technique was observed.

\section{Thresholds for Initiating Operative Treatment}

Figure $3 \mathrm{a}$ and $\mathrm{b}$ shows for each study the proportion of dentists reporting a restorative intervention at or before stage 3 occlusal caries lesions and stage 4 approximal car- 

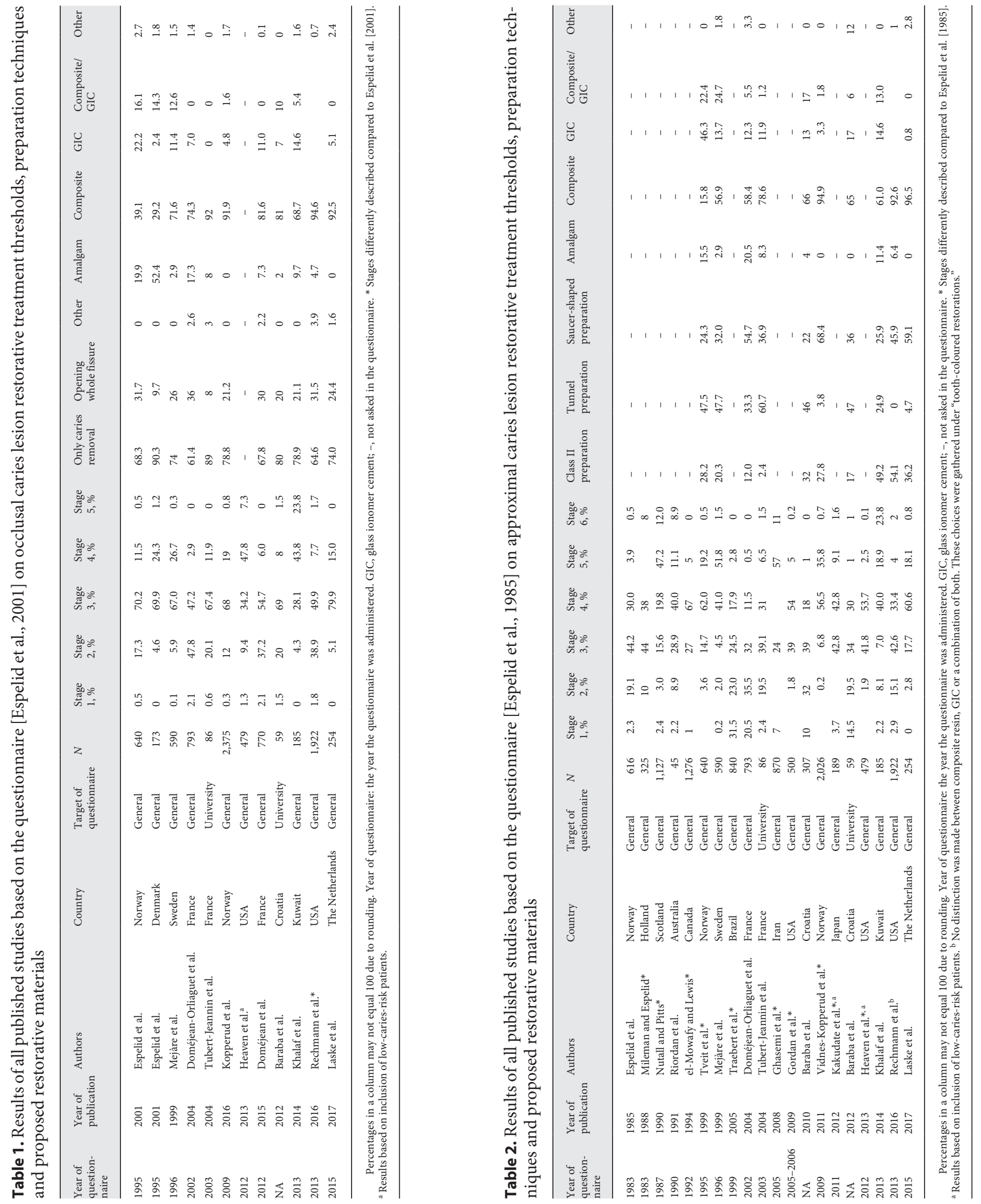
ies lesions. Data from time points at least 10 years apart were available for Norway (1983, 1995 and 2009), France (2002 and 2012) and the Netherlands (1983 and results from the present Dutch survey). In Norway, a reduction in the proportion of dentists is visible for both occlusal lesions (from $88.0 \%$ in 1995 to $80.2 \%$ in 2009) and approximal lesions (from $95.6 \%$ in 1983 over $80.3 \%$ in 1995 to $63.5 \%$ in 2009 ), indicating that more dentists are postponing interventions until the lesions have progressed to a deeper level. In France, a similar but weaker trend could be observed for occlusal lesions (from 97\% in 2002 to $94 \%$ in 2012). For approximal caries lesions, in the Netherlands a similar trend could also be observed (from $92 \%$ in 1983 to $81.1 \%$ in 2015). Relative outliers are visible in studies from 2012 (USA) and 2013 (Kuwait) and in studies from 1987 (Scotland) and 1996 (Sweden), where occlusal and approximal interventions, respectively, were predominantly postponed until frank cavitation.

\section{Preparation Techniques}

Figure $3 \mathrm{c}$ and $\mathrm{d}$ shows for each study the proportion of dentists preferring minimally invasive preparation techniques. In Norway (between 1995 and 2009) and France (between 2002 and 2012), a clear increase (from 10 to $20 \%$ ) in use of the carious-tissue-removal-only method was observed for occlusal lesions. For approximal lesions, a very strong trend was observed in Norway, with the reported use of the saucer-shaped preparation increasing from $24.3 \%$ in 1995 to $68.4 \%$ in 2009 . In contrast, Table 1 reveals that the standard class II preparation was still the most favoured preparation design reported for California and Kuwait even in 2013.

\section{Use of Restorative Materials}

Figure $3 \mathrm{e}$ and $\mathrm{f}$ shows the preferred restorative material reported in all studies. A linear trend line was drawn for the use of composite resin and amalgam. Across countries, a clear increase in the use of composite can be observed, with amalgam becoming almost extinct. Glass ionomer cement use (alone or in combination with composite) was only substantially reported between 1995 and 1999 in Scandinavia.

\section{Discussion}

The present study aimed to explore a possible worldwide trend towards a more minimally invasive strategy concerning operative interventions in primary caries lesions. For this purpose, the results from questionnaires

Minimally Invasive Caries Intervention, a Scattered Landscape designed by Espelid and Tveit [Espelid et al., 1985, 2001] were used. However, as the dates of the surveys vary considerably, differences in caries experience and social culture occur between countries and only for a limited number of countries two questionnaires could be compared across an interval of at least 10 years, it is difficult to draw any conclusions about worldwide trends. Within these limitations, we can clearly state that an international trend towards more minimally invasive strategies in the operative treatment of caries lesions could not be observed, neither regarding the initiation of operative treatment nor concerning preparation techniques. Figure $3 a-$ $\mathrm{d}$ shows a scattered landscape, mainly due to remarkable differences between countries. In the few cases in which we were able to compare results within the same country over time, some trends could be observed that will be discussed.

With the more recent insight that caries is not an infectious disease and (complete) carious tissue removal is not necessary [Ricketts et al., 2013], the recommended moment of operative intervention is when preventive measures such as biofilm control, remineralisation strategies and sealing are no longer expected to be successful [Marinho et al., 2013; Ricketts et al., 2013; Dorri et al., 2015]. As a current guideline, cavitated lesions are considered appropriate candidates for operative intervention [Meyer-Lueckel and Paris, 2016]. This would also include approximal lesions extending beyond the outer third of the dentine as observed on bitewing radiographs, since these are most likely cavitated, even if cavitation cannot normally be clinically detected [Meyer-Lueckel and Paris, 2016]. Therefore, in terms of the present questionnaire this would mean that stage 4 occlusal caries and stage 5 approximal caries would be the closest to a "gold standard" threshold for minimally invasive operative intervention.

The results reported over the years, as shown in Figure $3 a$ and $b$, suggest that there is still a gap between this scientific view on caries management and clinical practice, as the majority of dentists would intervene at stages 3 (occlusal) and 4 (proximal), although in some countries a slow shift towards later intervention can be observed. The most pronounced change was observed in Norway. In $1983,95.6 \%$ of the Norwegian dentists would have initiated operative treatment when caries was reaching the outer third of the dentin for approximal lesions. Over the years this percentage decreased to $80.3 \%$ in 1995 and $63.5 \%$ in 2009 , clearly indicating that Norwegian dentists are moving towards later intervention. A less clear trend was found in the Netherlands. In 1983, 92\% of the Dutch 


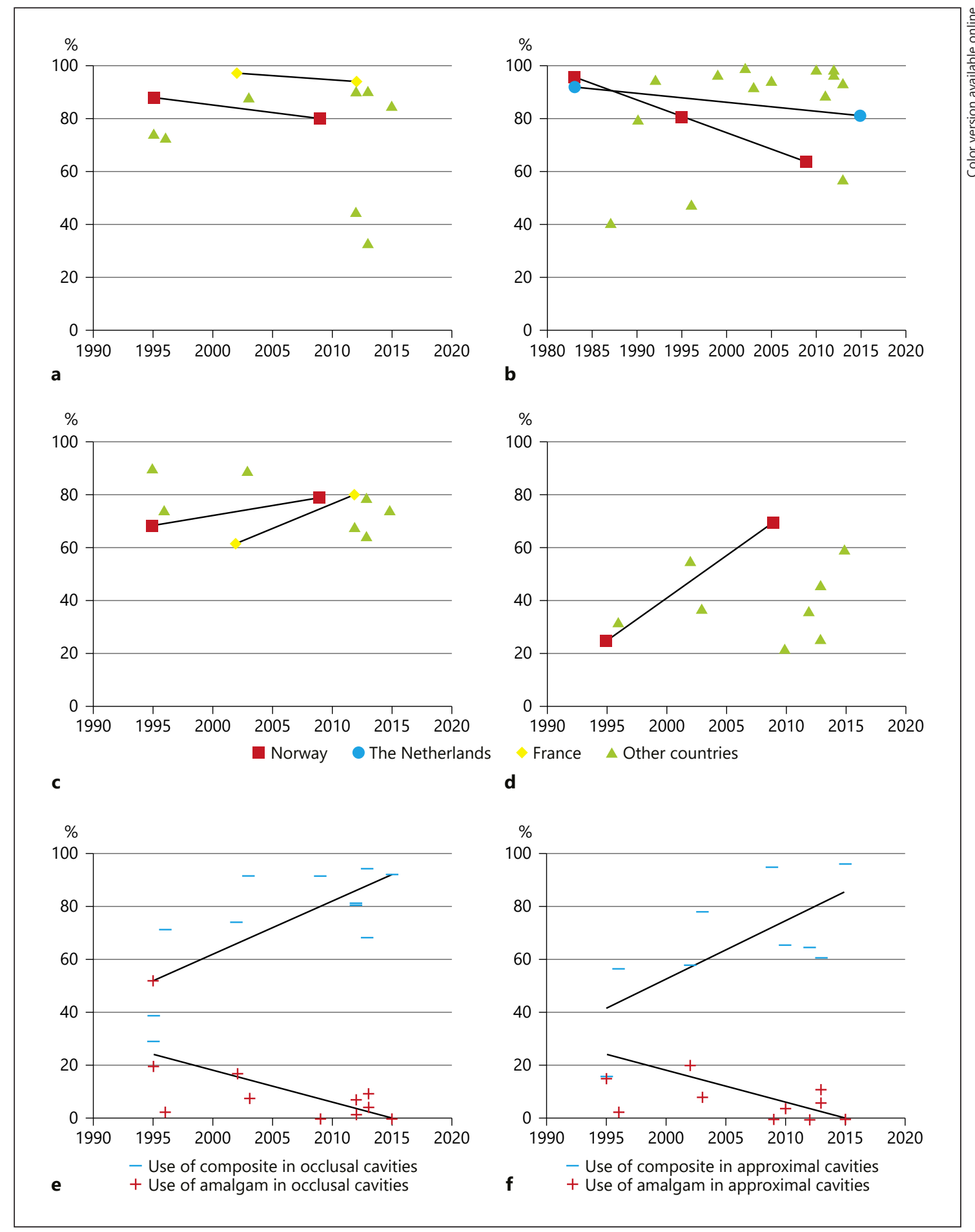

Fig. 3. Scatterplots from different studies for restorative threshold (\%), minimally invasive preparation technique (\%) and the preferred restorative material (\%) against the year the questionnaire was administered. a, b For each study, the proportion of dentists reporting restorative intervention at or before stage 3 occlusal caries lesions (a) and approximal stage 4 lesions (b) is shown. c, d For each study, the proportion of dentists preferring only occlusal caries removal (c) and an approximal saucer-shaped preparation (d) is shown. e, f For occlusal (e) and approximal (f) cavities, the proportion of dentists preferring a composite resin or amalgam restoration is shown. 
dentists would have intervened restoratively in a stage 4 approximal caries lesion, while by 2015 this percentage decreased to $81.1 \%$, indicating that the majority of dentists in the Netherlands still tend to intervene at a too early stage in proximal caries.

As far as interventions for occlusal lesions are concerned, Norway and France both show a slight decrease in early interventions. However, French dentists seem to be more eager to intervene than dentists from the other countries studied, as both in 2002 and 2012 more than 94\% of the questioned French dentists would have intervened as soon as caries had reached the dentin. The development of caries management in the USA is more difficult to assess, because the surveys there were conducted in different states and over a shorter time span (2005, 2012 and 2013). However, in all 3 surveys more than $90 \%$ of the studied American dentists would have intervened restoratively in caries lesions confined to the outer third of the dentin. The scatter plot in Figure 2 suggests there is a tendency that when dentists are intervening at a later stage of the occlusal caries process, they are also more likely to use a minimally invasive preparation technique. However, this result was not statistically significant, and Kuwait was found as a relative outlier. These results could be related to the fact that almost all countries evaluated present a limited caries experience. Practising dentists in countries with a high caries prevalence are more used to intervening at a later stage of the caries process and have fewer possibilities for controlling progressive demineralization and caries lesion progression.

These results confirm longstanding differences in preventive orientation, with the Scandinavian countries having formed the vanguard for many decades. An explanation for the scattered landscape regarding decision-making especially between countries is difficult to give, as several factors may be responsible that have not been investigated yet. Differences in reimbursement systems, nationwide caries experience, the age of the dentist population, the presence of a dental public health service or the dentist-patient ratio may be responsible for the delayed implementation of novel developments among dentists.

It may be assumed that in the university environment of dental schools, the implementation of new evidencebased treatment is likely to precede its spread in general dental practice, and that therefore a younger population of dentists will more likely have been exposed to these changing guidelines. The Dutch dentist population is relatively old, which matches the observation that they still intervene relatively early, especially in proximal lesions. Rechmann et al. [2016] observed a trend among younger

Minimally Invasive Caries Intervention, a Scattered Landscape
Californian dentists to intervene at a later stage when compared to their older colleagues, which supports this assumption and may also have played a role in the US results. Differences in occlusal and approximal caries management between teachers at university and general dental practitioners in France and Croatia have been found. The threshold for operative treatment among teachers is at a more advanced stage of caries lesion than among French general dental practitioners [Doméjean-Orliaguet et al., 2004; Tubert-Jeannin et al., 2004]. Also, more minimally invasive preparation techniques and the use of composite are more popular at French universities than in general dental practices. In Croatia, no differences were found regarding restoration thresholds or proposed restorative materials, but the saucer-shaped preparation was more preferred at university (36\%) than in private practice (22\%) [Baraba et al., 2010, 2012].

The response rate (27\%) in the 2015 Dutch national survey was lower than that obtained with a similar questionnaire in 1983 (77\%), which can be seen as a limitation to the results of the present national survey. Nevertheless, the current data provide a general demographically representative data set, as shown in Appendix 2. A statistically significant correlation regarding when to intervene in approximal and occlusal caries was shown (Figure 1). This indicates that practitioners who are more eager to intervene at an early stage of approximal caries are also more eager to do so in case of occlusal caries. These findings are in line with previous studies [Mejàre et al., 1999; Espelid et al., 2001; Kopperud et al., 2016].

As far as preparation techniques are concerned, the caries-removal-only technique has generally been preferred for the past 20 years by more than half of the dentists. No overall trend can be observed, although this technical preference increased by $10.5 \%$ among dentists over a period of 14 years in Norway and by $17 \%$ among dentists over a period of 11 years in France. In Norway, the preference for a saucer-shaped preparation almost tripled to $68.4 \%$ between 1995 and 2009. From the results of the last decade, only in Norway and the Netherlands the saucer-shaped preparation design has been the most favoured technique, while overall the traditional class II preparation is still quite popular.

However, a worldwide shift in the restoration of primary caries lesions, i.e., from amalgam towards composite resin, could be observed in the present study, as illustrated in Figure $3 \mathrm{e}$ and $\mathrm{f}$. From the data it becomes clear that composite resin has replaced amalgam as the preferred material for the restoration of primary caries lesions in the Netherlands, Norway, France and California 
(USA), where tooth-coloured restorations were preferred by more than $90 \%$ of the dentists. These findings are in accordance with other studies [Sunnegårdh-Grönberg et al., 2009; Eklund, 2010]. On January 1, 2008, the use of amalgam was banned in Norway, and in the most recent surveys [Vidnes-Kopperud et al., 2011; Kopperud et al., 2016] it was not an option anymore. Glass ionomer cement reached some popularity as the preferred material for restoring primary caries lesions especially in Northern European countries, although its use decreased overtime. However, it is doubtful whether this shift is driven by a more minimally invasive approach of the dentists. It may well be that the WHO recommendation to decrease the use of amalgam and the increased demand of patients for aesthetically pleasing restorations are the reasons for this [FDI World Dental Federation, 2014].

Summarising this overview of the survey results, the following conclusions can be made: Large variations in restorative decisions at which stage to intervene in proximal and occlusal primary caries exist around the world. Generally, dentists decide on operative interventions at too early a stage. In countries where changes over time could be assessed, and especially in Norway, an increasing minimally invasive attitude could be observed. Composite resin has almost completely replaced amalgam for restoring primary caries lesions.

\section{Acknowledgements}

The authors acknowledge the Royal Dutch Dental Association (KNMT) for their financial support in data collection. The funders had no role in the study design, data collection and analysis, the decision to publish, or the preparation of the manuscript.

\section{Statement of Ethics}

The design and the protocol were approved by the local ethics committee (METC; CMO Arnhem-Nijmegen, file Nr. 2016-2556).

\section{Disclosure Statement}

The authors declare no conflict of interest.

\section{Author Contributions}

All the authors had a part in the preparation of the manuscript.

\section{Appendix 1}

Questionnaire

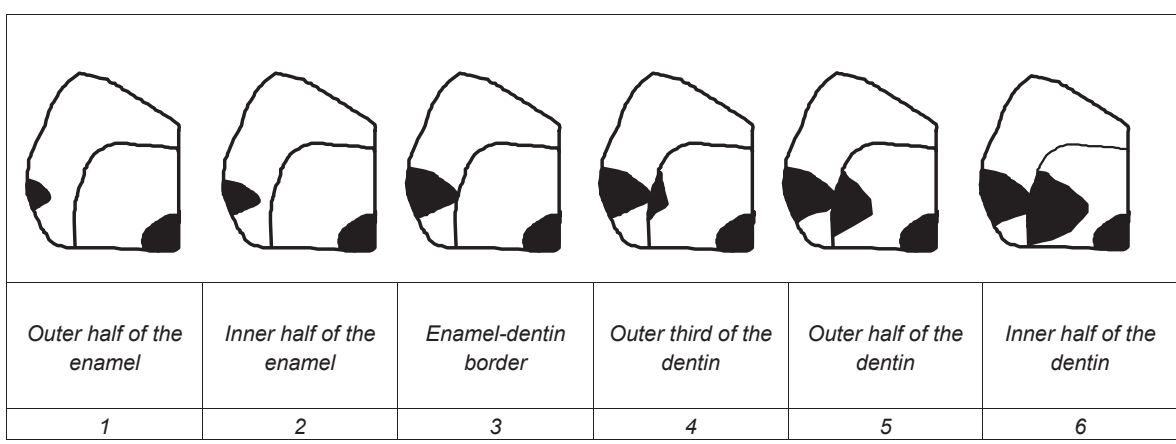

Fig. 1. Illustration of the different stages of approximal caries progression (stages 1-6) 
Table 1. Questions regarding approximal carious lesions

Case 1 These pictures illustrate different stages of caries progression on the distal surface of tooth 15 or 25 . Imagine a

Approximal 20-year-old patient with low caries activity, good oral hygiene, visiting a dentist annually and brushing twice a day lesion with a fluoridated toothpaste

\begin{tabular}{ll}
\hline A & Starting at which stage do you think an approximal restoration is indicated? (1-6) \\
\hline B & Which type of preparation would you prefer for the restoration of the lesion at your chosen stage? (1-3) \\
& 1: Traditional black class II preparation, 2: Tunnel preparation, 3: Chamfer preparation, saucer-shaped preparation \\
\hline C & Which restorative material would you prefer for the restoration of the lesion at your chosen stage? (1-5) \\
& 1: Amalgam, 2: Glass ionomer, 3: Composite resin, 4: Compomer, 5: Other
\end{tabular}
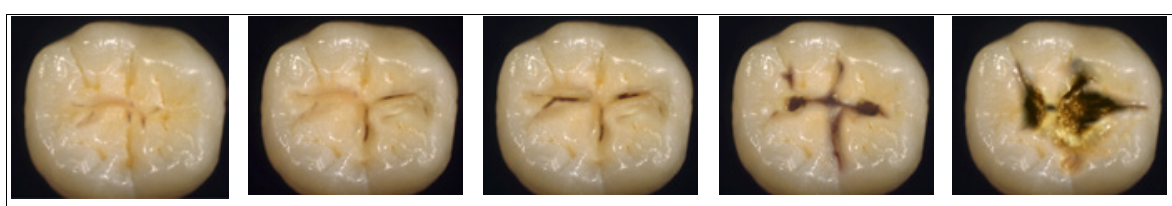

\begin{tabular}{|c|c|c|c|c|}
\hline $\begin{array}{l}\text { - White or discoloured } \\
\text { enamel, no caviation } \\
\text { clinically } \\
\text { - No radiographic } \\
\text { signs of caries }\end{array}$ & $\begin{array}{l}\text { - Small cavitation } \\
\text { clinically } \\
\text { - No radiographic } \\
\text { signs of caries }\end{array}$ & $\begin{array}{l}\text { - Moderate sized loss } \\
\text { of tooth structure } \\
\text { - Radiolucency in the } \\
\text { outer third of the } \\
\text { dentin }\end{array}$ & $\begin{array}{l}\text { - Large sized loss of } \\
\text { tooth structure } \\
\text { - Radiolucency in the } \\
\text { middle third of the } \\
\text { dentin }\end{array}$ & $\begin{array}{l}\text { - Extensive sized loss } \\
\text { of tooth structure } \\
\text { - Radiolucency in the } \\
\text { inner third of the } \\
\text { dentin }\end{array}$ \\
\hline 1 & 2 & 3 & 4 & 5 \\
\hline
\end{tabular}

Fig. 2. Illustration of the different stages of occlusal caries progression (stages 1-5)

Table 2. Questions regarding occlusal carious lesions

\begin{tabular}{ll}
\hline $\begin{array}{l}\text { Case 2 } \\
\text { Occlusal lesion }\end{array}$ & $\begin{array}{l}\text { These pictures illustrate different stages of caries progression on the distal surface of tooth } 15 \text { or } 25 . \text { Imagine a } \\
\text { 20-year-old patient with low caries activity, good oral hygiene, visiting a dentist annually and brushing twice a day } \\
\text { with a fluoridated toothpaste }\end{array}$ \\
\hline A & Starting at which stage do you think an occlusal restoration is indicated? (1-5) \\
\hline B & $\begin{array}{l}\text { Which type of preparation would you prefer for the restoration of the lesion at your chosen stage? (1-3) } \\
\text { 1: Only carious tissue removal, 2: Opening whole fissure, 3: Other }\end{array}$ \\
\hline C & $\begin{array}{l}\text { Which restorative material would you prefer for the restoration of the lesion at your chosen stage? (1-5) } \\
\text { 1: Amalgam, 2: Glass ionomer, 3: Composite resin, 4: Compomer, 5: Other }\end{array}$ \\
\hline
\end{tabular}

Minimally Invasive Caries Intervention, a Scattered Landscape 


\section{Appendix 2}

Representativeness of the Collected Data: Individual Background Characteristics of the Non-Respondents and Respondents in the Sample from the Dutch Survey

\begin{tabular}{|c|c|c|c|}
\hline & Non-respondents & Respondents & Total sample \\
\hline \multicolumn{4}{|l|}{ Sex $(d f=1 / p=0.393 /$ Cramér's $V=0.027)$} \\
\hline Male & $63 \%$ & $66 \%$ & $64 \%$ \\
\hline \multicolumn{4}{|c|}{ Age on January $1,2015(\mathrm{df}=4 / p=0.002 /$ Cramér's $\mathrm{V}=0.130)$} \\
\hline 29 years or younger & $6 \%$ & $10 \%$ & $10 \%$ \\
\hline $50-59$ years & $41 \%$ & $30 \%$ & $30 \%$ \\
\hline 60 years or older & $20 \%$ & $16 \%$ & $16 \%$ \\
\hline Mean age $\left(\mathrm{df}=1 / p=0.000 / \eta^{2}=0.009\right)$ & 44.5 years & 47.1 years & 45.2 years \\
\hline \multicolumn{4}{|l|}{ Place of graduation $(\mathrm{df}=5 / p=0.065 /$ Cramér's $\mathrm{V}=0.102)$} \\
\hline Amsterdam & $39 \%$ & $33 \%$ & $37 \%$ \\
\hline \multicolumn{4}{|l|}{ Year of graduation $(\mathrm{df}=4 / p=0.002 /$ Cramér's $\mathrm{V}=0.130)$} \\
\hline 1979 or earlier & $9 \%$ & $18 \%$ & $11 \%$ \\
\hline 1980-1989 & $30 \%$ & $34 \%$ & $31 \%$ \\
\hline 1990-1999 & $17 \%$ & $13 \%$ & $16 \%$ \\
\hline 2000-2009 & $33 \%$ & $25 \%$ & $31 \%$ \\
\hline 2010 or later & $11 \%$ & $10 \%$ & $11 \%$ \\
\hline Mean year of graduation $\left(\mathrm{df}=1 / p=0.003 / \eta^{2}=0.013\right)$ & 1995.1 & 1992.1 & 1994.3 \\
\hline \multicolumn{4}{|c|}{ Region of establishmenta $(\mathrm{df}=3 / p=0.251 /$ Cramér's $\mathrm{V}=0.064)$} \\
\hline North & $9 \%$ & $11 \%$ & $10 \%$ \\
\hline East & $20 \%$ & $21 \%$ & $20 \%$ \\
\hline South & $20 \%$ & $22 \%$ & $21 \%$ \\
\hline No & $48 \%$ & $45 \%$ & $47 \%$ \\
\hline \multirow[t]{2}{*}{ Total $^{\mathrm{b}}$} & 714 & 227 & 991 \\
\hline & $72 \%$ & $28 \%$ & $100 \%$ \\
\hline \multicolumn{4}{|c|}{$\begin{array}{l}\text { The sample consisted of } 1,050 \text { dentists aged } 64 \text { years or younger (January 2014) with a known place of residence and/or work in th } \\
\text { Netherlands. Those dentists were asked by email to answer the Web questionnaire. A total of } 55 \text { dentists from the sample were n } \\
\text { reached (bouncers: autoreply, wrong or unknown email address). The net sample therefore consisted of } 995 \text { dentists. a The region } \\
\text { establishment is based on the division of the Netherlands into KNMT departments. Here the "south" region is formed by sections } 1 \\
13 \text { and 14, the "west" region by sections } 5,7,8,9,10 \text { and } 11 \text {, the "east" region by sections } 3,4 \text { and } 6 \text {, and the "north" region by section } \\
1 \text { and 2. " Four people were found to be unidentifiable (completely anonymous). }\end{array}$} \\
\hline
\end{tabular}




\section{Appendix 3}

Associations between Selected Variables and the Odds of Restoring Stage 3 Occlusal Caries Operatively from the Dutch Survey

\begin{tabular}{|c|c|c|c|c|}
\hline \multirow[t]{2}{*}{ Independent variable } & \multirow{2}{*}{$\begin{array}{l}\text { Subjects, } \\
n(\%)\end{array}$} & \multicolumn{2}{|c|}{ Unadjusted } & \multirow[t]{2}{*}{$p$ value } \\
\hline & & OR & $95 \% \mathrm{CI}$ & \\
\hline \multicolumn{5}{|l|}{ Gender } \\
\hline Female & $87(34.3)$ & 1.002 & $0.485-2.073$ & 0.995 \\
\hline Male & $167(65.7)$ & & & \\
\hline Experience & & & & 0.309 \\
\hline $0-5$ years & $24(9.4)$ & 4.351 & $0.543-34.900$ & 0.166 \\
\hline $6-15$ years & $66(26.0)$ & 1.372 & $0.539-3.491$ & 0.507 \\
\hline $16-30$ years & $76(29.9)$ & 0.769 & $0.345-1.718$ & 0.522 \\
\hline$\geq 31$ years & $88(34.6)$ & & & \\
\hline \multicolumn{5}{|l|}{ Graduation } \\
\hline Abroad & $33(13)$ & 1.882 & $0.544-6.506$ & 0.318 \\
\hline The Netherlands & $221(87)$ & & & \\
\hline Preparation technique & & & & 0.811 \\
\hline Open the whole fissure & $92(36.2)$ & 1.282 & $0.554-2.965$ & 0.562 \\
\hline Other & $12(4.7)$ & - & - & $0.590^{*}$ \\
\hline Removal of carious tissue only & $150(59.1)$ & & & \\
\hline \multicolumn{5}{|l|}{ Filling material } \\
\hline Amalgam, GIC and others & $9(3.5)$ & 0.457 & $0.155-1.354$ & 0.158 \\
\hline Composite & $245(96.5)$ & & & \\
\hline
\end{tabular}

\section{Appendix 4}

Associations between Selected Variables and the Odds of Restoring Stage 4 Approximal Caries Operatively from the Dutch Survey

\begin{tabular}{|c|c|c|c|c|}
\hline \multirow[t]{2}{*}{ Independent variable } & \multirow{2}{*}{$\begin{array}{l}\text { Subjects, } \\
n(\%)\end{array}$} & \multicolumn{2}{|c|}{ Unadjusted } & \multirow[t]{2}{*}{$p$ value } \\
\hline & & OR & $95 \% \mathrm{CI}$ & \\
\hline \multicolumn{5}{|l|}{ Gender } \\
\hline Female & $87(34.3)$ & 1.182 & $0.602-2.320$ & 0.627 \\
\hline Male & $167(65.7)$ & & & \\
\hline Experience & & & & 0.120 \\
\hline $0-5$ years & $24(9.4)$ & 1.567 & $0.481-5.101$ & 0.456 \\
\hline $6-15$ years & $66(26.0)$ & 3.134 & $1.186-8.284$ & 0.021 \\
\hline $16-30$ years & $76(29.9)$ & 1.088 & $0.525-2.255$ & 0.821 \\
\hline$\geq 31$ years & $88(34.6)$ & & & \\
\hline \multicolumn{5}{|l|}{ Graduation } \\
\hline Abroad & $33(13)$ & - & - & $0.003^{*}$ \\
\hline The Netherlands & $221(87)$ & & & \\
\hline Preparation technique & & & & 0.055 \\
\hline Traditional class II preparation & $92(36.2)$ & 2.496 & $1.170-5.324$ & 0.018 \\
\hline Tunnel preparation & $12(4.7)$ & 0.913 & $0.234-3.559$ & 0.896 \\
\hline Saucer-shaped preparation & $150(59.1)$ & & & \\
\hline \multicolumn{5}{|l|}{ Filling material } \\
\hline Amalgam, GIC and others & $9(3.5)$ & 1.899 & $0.232-15.555$ & 0.550 \\
\hline Composite & $245(96.5)$ & & & \\
\hline
\end{tabular}




\section{References}

Baraba A, Doméjean-Orliaguet S, Espelid I, Tveit AB, Miletic I: Survey of Croatian dentists' restorative treatment decisions on approximal caries lesions. Croat Med J 2010;51:509-514.

Baraba A, Doméjean S, Jurić H, Espelid I, Tveit $\mathrm{AB}$, Anić I: Restorative treatment decisions of Croatian university teachers. Coll Antropol 2012;36:1293-1299.

Doméjean-Orliaguet S, Tubert-Jeannin S, Riordan PJ, Espelid I, Tveit AB: French dentists' restorative treatment decisions. Oral Health Prev Dent 2004;2:125-131.

Doméjean S, Léger S, Maltrait M, Espelid I, Tveit $A B$, Tubert-Jeannin S: Changes in occlusal caries lesion management in France from 2002 to 2012: a persistent gap between evidence and clinical practice. Caries Res 2015; 49:408-416.

Dorri M, Dunne SM, Walsh T, Schwendicke F: Micro-invasive interventions for managing proximal dental decay in primary and permanent teeth. Cochrane Database Syst Rev 2015; 11:CD010431.

Eklund SA: Trends in dental treatment, 1992 to 2007. J Am Dent Assoc 2010;141:391-399.

el-Mowafy OM, Lewis DW: Restorative decision making by Ontario dentists. J Can Dent Assoc 1994;60:305-310, 313-316.

Espelid I, Tveit A, Haugejorden O, Riordan PJ: Variation in radiographic interpretation and restorative treatment decisions on approximal caries among dentists in Norway. Community Dent Oral Epidemiol 1985;13:26-29.

Espelid I, Tveit AB, Mejàre I, Sundberg $\mathrm{H}, \mathrm{Hal}-$ lonsten AL: Restorative treatment decisions on occlusal caries in Scandinavia. Acta Odontol Scand 2001;59:21-27.

Frencken JE, Peters MC, Manton DJ, Leal SC, Gordan VV, Eden E: Minimal intervention dentistry for managing dental caries - a review: report of a FDI task group. Int Dent J 2012;62:223-243.

FDI World Dental Federation: FDI policy statement on dental amalgam and the Minamata Convention on Mercury: adopted by the FDI General Assembly: 13 September 2014, New Delhi, India. Int Dent J 2014;64:295-296.

Ghasemi H, Murtomaa H, Torabzadeh H, Vehkalahti MM: Restorative treatment threshold reported by Iranian dentists. Community Dent Health 2008;25:185-190.

Gordan VV, Garvan CW, Heft MW, Fellows JL, Qvist V, Rindal DB, Gilbert GH; DPBRN Collaborative Group: Restorative treatment thresholds for interproximal primary caries based on radiographic images: findings from the Dental Practice-Based Research Network. Gen Dent 2009;57:654-663; quiz 664-666, $595,680$.

Gröndahl HG, Andersson B, Torstensson T: Caries increment and progression in teenagers when using a prevention- rather than restoration-oriented treatment strategy. Swed Dent J $1984 ; 8: 237-242$.
Heaven TJ, Gordan VV, Litaker MS, Fellows JL, Brad Rindal D, Firestone AR, Gilbert GH; National Dental PBRN Collaborative Group: Agreement among dentists' restorative treatment planning thresholds for primary occlusal caries, primary proximal caries, and existing restorations: findings from The National Dental Practice-Based Research Network. J Dent 2013;41:718-725.

Hörsted-Bindslev P, Heyde-Petersen B, Simonsen P, Baelum V: Tunnel or saucer-shaped restorations: a survival analysis. Clin Oral Investig 2005;9:233-238.

Innes NPT, Schwendicke F: Restorative thresholds for carious lesions: systematic review and meta-analysis. J Dent Res 2017;96:501-508.

Kakudate N, Sumida F, Matsumoto Y, Manabe K, Yokoyama Y, Gilbert GH, Gordan VV: Restorative treatment thresholds for proximal caries in dental PBRN. J Dent Res 2012;91: 1202-1208.

Kassebaum NJ, Bernabé E, Dahiya M, Bhandari B, Murray CJ, Marcenes W: Global burden of untreated caries: a systematic review and metaregression. J Dent Res 2015;94:650-658.

Khalaf ME, Alomari QD, Ngo H, Doméjean S: Restorative treatment thresholds: factors influencing the treatment thresholds and modalities of general dentists in Kuwait. Med Princ Pract 2014;23:357-362.

Kidd EA, Pitts NB: A reappraisal of the value of the bitewing radiograph in the diagnosis of posterior approximal caries. Br Dent J 1990; 169:195-200

Kopperud SE, Tveit AB, Opdam NJ, Espelid I: Occlusal caries management: preferences among dentists in Norway. Caries Res 2016;50:4047.

Listl S, Galloway J, Mossey PA, Marcenes W: Global economic impact of dental diseases. J Dent Res 2015;94:1355-1361.

Lussi A: Validity of diagnostic and treatment decisions of fissure caries. Caries Res 1991;25: 296-303.

Marcenes W, Kassebaum NJ, Bernabé E, Flaxman A, Naghavi M, Lopez A, Murray CJ: Global burden of oral conditions in 1990-2010: a systematic analysis. J Dent Res 2013;92:592-597.

Marinho VC, Worthington HV, Walsh T, Clarkson JE: Fluoride varnishes for preventing dental caries in children and adolescents. Cochrane Database Syst Rev 2013;7:CD002279.

Mejàre I, Sundberg H, Espelid I, Tveit B: Caries assessment and restorative treatment thresholds reported by Swedish dentists. Acta Odontol Scand 1999;57:149-154.

Meyer-Lueckel H, Paris S: When and how to intervene in the caries process. Oper Dent 2016; 41:S35-S47.
Mileman PA, Espelid I: Decisions on restorative treatment and recall intervals based on bitewing radiographs. A comparison between national surveys of Dutch and Norwegian practitioners. Community Dent Health 1988; 273-284.

Nicolaisen S, von der Fehr FR, Lunder N, Thomsen I: Performance of tunnel restorations at 3-6 years. J Dent 2000;28:383-387.

Nuttall NM, Pitts NB: Restorative treatment thresholds reported to be used by dentists in Scotland. Br Dent J 1990;169:119-126.

Penning C, van Amerongen JP, Seef RE, ten Cate JM: Validity of probing for fissure caries diagnosis. Caries Res 1992;26:445-449.

Pitts NB: Monitoring of caries progression in permanent and primary posterior approximal enamel by bitewing radiography. Community Dent Oral Epidemiol 1983;11:228-235.

Rechmann P, Doméjean S, Rechmann BM, Kinsel R, Featherstone JD: Approximal and occlusal carious lesions: restorative treatment decisions by California dentists. J Am Dent Assoc 2016;147:328-338.

Ricketts D, Lamont T, Innes NP, Kidd E, Clarkson JE: Operative caries management in adults and children. Cochrane Database Syst Rev 2013;3:CD003808

Riordan PJ, Espelid I, Tveit AB: Radiographic interpretation and treatment decisions among dental therapists and dentists in Western Australia. Community Dent Oral Epidemiol 1991;19:268-271

Schwendicke F, Frencken JE, Bjørndal L, Maltz M, Manton DJ, Ricketts D, Van Landuyt K, Banerjee A, Campus G, Doméjean S, Fontana M, Leal S, Lo E, Machiulskiene V, Schulte A, Splieth C, Zandona AF, Innes NP: Managing carious lesions: consensus recommendations on carious tissue removal. Adv Dent Res 2016; 28:58-67.

Strand GV, Nordbø H, Leirskar J, von der Fehr FR, Eide GE: Tunnel restorations placed in routine practice and observed for 24 to 54 months. Quintessence Int 2000;31:453-460.

Sunnegårdh-Grönberg K, van Dijken JW, Funegård $\mathrm{U}$, Lindberg $\mathrm{A}$, Nilsson $\mathrm{M}$ : Selection of dental materials and longevity of replaced restorations in Public Dental Health clinics in northern Sweden. J Dent 2009;37:673-678.

Traebert J, Marcenes W, Kreutz JV, Oliveira R, Piazza CH, Peres MA: Brazilian dentists' restorative treatment decisions. Oral Health Prev Dent 2005;3:53-60.

Tubert-Jeannin S, Doméjean-Orliaguet S, Riordan PJ, Espelid I, Tveit AB: Restorative treatment strategies reported by French university teachers. J Dent Educ 2004;68:1096-1103.

Tveit AB, Espelid I, Skodje F: Restorative treatment decisions on approximal caries in Norway. Int Dent J 1999;49:165-172.

Vidnes-Kopperud S, Tveit AB, Espelid I: Changes in the treatment concept for approximal caries from 1983 to 2009 in Norway. Caries Res 2011;45:113-120. 